\title{
Title: Liquid Metal Focused Ion Beam Sensitization and Related Data Transmission Processes
}

Author(s):

B. C. Lamartine, MST-7

\section{Los Alamos}

NATIONAL LABORATORY

Los Alamos National Laboratory, an affirmative action/equal opportunity employer, is operated by the University of Calitornia for the U.S. Department of Energy under contract W-7405-ENG-36. By acceptance of this article, the publisher recognizes that the U.S. Government retains a nonexclusive, royaltyfree license to pubtsh or reproduce the published form of this contribution, or to allow others to do so, for U.S. Government purposes. Los Alamos National Laboratory requests that the publisher identify this anticle as work periormed under the auspices of the U.S. Department of Energy. Los Alamos National Laboratory strongly supports academic freedom and a researcher's right to publish; as an institution, however, the Laboratory does not endorse the viewpoirt of a publication or guarantee its technical correctness. 


\section{DISCLAIMER}

This report was prepared as an account of work sponsored by an agency of the United States Government. Neither the United States Government nor any agency thereof, nor any of their employees, makes any warranty, express or implied, or assumes any legal liability or responsibility for the accuracy, completeness, or usefulness of any information, apparatus, product, or process disclosed, or represents that its use would not infringe privately owned rights. Reference herein to any specific commercial product, process, or service by trade name, trademark, manufacturer, or otherwise does not necessarily constitute or imply its endorsement, recommendation, or favoring by the United States Government or any agency thereof. The views and opinions of authors expressed herein do not necessarily state or reflect those of the United States Government or any agency thereof. 


\section{DISCLAMVER}

Portions of this doewenent may be Illegible in electronic image products Images are produced from the best available original docomentert 


\title{
Liquid Metal Focused Ion Beam Etch Sensitization and Related Data Transmission Processes
}

\author{
Bruce C. Lamartine* \\ Materials Science and Technology Division
}

\begin{abstract}
This is the final report of a one-year, Laboratory Directed Research and Development (LDRD) project at Los Alamos National Laboratory (LANL). The ion micromilling process, while already successful, can be enhanced by ion beam sensitization to wet or dry anisotropic chemical etch reactions. The ion beam sensitization is unique from conventional lithography in that many levels of feature depth are potentially available (depending on the local spatial ion dose) and that no organic or inorganic resist is required. This process is applicable to the production of both digital and human-readable grey-scale data on archival media, such as silicon or other single crystals or amorphous coatings. Furthermore, it has been shown that a suitable micromachined data medium having an appropriate format can be read by (1) a phase-sensitive interference microscope, (2) a laser intensity feedback microscope, or (3) a conventional scanning electron microscope.
\end{abstract}

\section{Background and Research Objectives}

Present data storage systems rely on media that use either magnetic or organic materials; consequently, media life is affected by RF/magnetic fields or high temperatures. In a previously filed patent application, we reported a number of data media (known collectively as HD-ROM, or high density read-only memory) employing such robust materials as iridium, titanium, copper, and silicon. Data were stored at densities limited only by the ion beam spot size. Physical data densities greater than 23 gigabits per square inch were reported. In addition, no bitstream interpreter was required to recover anolog or grey-scale data. Still, to be commercially attractive, faster writing speeds were imperative. While some enhancement in writing speed can be achieved by simply increasing the current of an ion column, batch chemical enhancements appeared far more attractive because of the extremely low ion doses required. Furthermore, chemical enhancements could always later be coupled with columns of higher current.

\footnotetext{
*Principal Investigator (E-mail: lamartine @lanl.gov)
} 
Importance to LANL's Science and Technology Base and National R\&D Needs

Anyone who generates archives needs reliable, long-lasting systems for data storage. Some obvious applications of the HD-ROM are in the areas of finance (bank transaction records), geology (seismic records and oil deposit mapping), defense (surveillance mapping), astrophysics (catalogs of objects and events), entertainment (audio and video masters), and the laboratory core programs (component and systems drawings, test archives).

\section{Scientific Approach and Accomplishments}

A number of authors [1-3] have reported the phenomenon of etch rate alteration using ion beams for anisotropic sensitization of a subsequent wet caustic etch. The underlying mechanism for such kinetic alteration was not clear, and most authors attributed the behaviour to either an increased reactive surface area due to ion damage tracks or normal bulk concentration effects. It was evident that a further examination and understanding of this chemical mechanism was necessary in order to produce graded depth data storage media. We undertook, therefore, both a theoretical and experimental examination of the ion sensitized etch phenomenon.

\section{Theoretical}

Wet etching in a uniform crystal can be envisioned as a layer-by-layer process. Here, the reaction rate of each layer is unique owing to both the dopant concentration in each layer and the electrochemical potential therefrom. Unlike bulk systems, the dopant concentration from ion implantation is distributed in approximately a Gaussian profile. The exact concentration profile for $25 \mathrm{KeV}$ gallium in silicon (100) was reported by Gnaser, et al. [4].

Further, the use of surface potential models for adsorbed layers has been reported by Lamartine and Eyink [5]. An interesting result of that work was that surface potentials of many submonolayer adatom coverages reached a minimum at some fraction of a monolayer and then stabilized at some higher value. The implication for etching is that, for shallow implants, there are regions where either enhancement (at low ion dosage) or retardation (at high ion dosage) of the reaction rate could be expected. Figure 1 shows calculations of enhancement and retardation of the relative reaction rate of sodium hydroxide on gallium-implanted silicon (100). Consideration of this plot suggests that 
variation of ion dose over 2-3 orders of magnitude should reveal the regions of altered behaviour.

\section{Experimental}

A computer-aided manufacturing (CAM) file was programmed for the LANL focused-ion-beam system wherein the interval of dose from 0 to $3 \times 10^{13}$ ions $/ \mathrm{cm}^{2}$ was partitioned into 16 intervals (see Fig.2). Under CAM control, the ion beam then exposed silicon (100). Subsequent etch in $\mathrm{NaOH}$ produced graded depth patterns typefied by the Mirau interferogram in Fig. 3. A cross section of the Mirau inteferogram is shown in Fig. 4. As predicted, regions of both enhanced and retarded etch rate were revealed. Subsequently, a dosing algorithm for linear grey scale was generated for both positive and negative analog images. We estimated an effective writing rate improvement factor of about 600 over the LANL focused ion beam operating in the conventional milling mode at a current density of $3 \mathrm{amps} / \mathrm{cm}^{2}$. Improvements in column current density could increase this writing rate by another factor of 10 . Ultimately, the writing rate is limited by the flight time of the ion and not the current density. At present, with available state-of-the-art equipment, one can estimate a digital writing rate of about 3.4 megabytes/sec in silicon with the etch enhancement after the fact. The working distance of the ion column and the acceleration potential may still be further improved for writing purposes.

Norsam Technologies, Inc., a Santa Fe, New Mexico startup company, has licensed the invention of etch stop enhancements for data writing in advance of completed US Patent Office actions and is now in the process of alpha testing the method on a stateof-the-art ion column system made by their partners, FEI Corporation of Hillsboro, Oregon, and Philips Corporation of Eindhoven, Netherlands.

\section{Publication}

"Depth Enhancement of Ion Sensitized Data," Bruce C. Lamartine, sole inventor, DOE Case \# 84,941. Completed patent pending, initial claims allowed by USPO. 


\section{References}

1. K.M. Edenfeld, et al., J. Vac. Sci. Technol., B12 3571 (1994).

2. P.H. LaMarche, et al., J. Vac. Sci. Technol., B1 1056 (1983).

3. I.L. Berry and A.L. Caviglia, J. Vac. Sci. Technol., B1 1059 (1983).

4. H. Gnaser, et al., J. Vac. Sci. Technol., B13 19 (1995).

5. B.C. Lamartine and K.G. Eyink, Appl. Surf. Sci., 21210 (1985). 


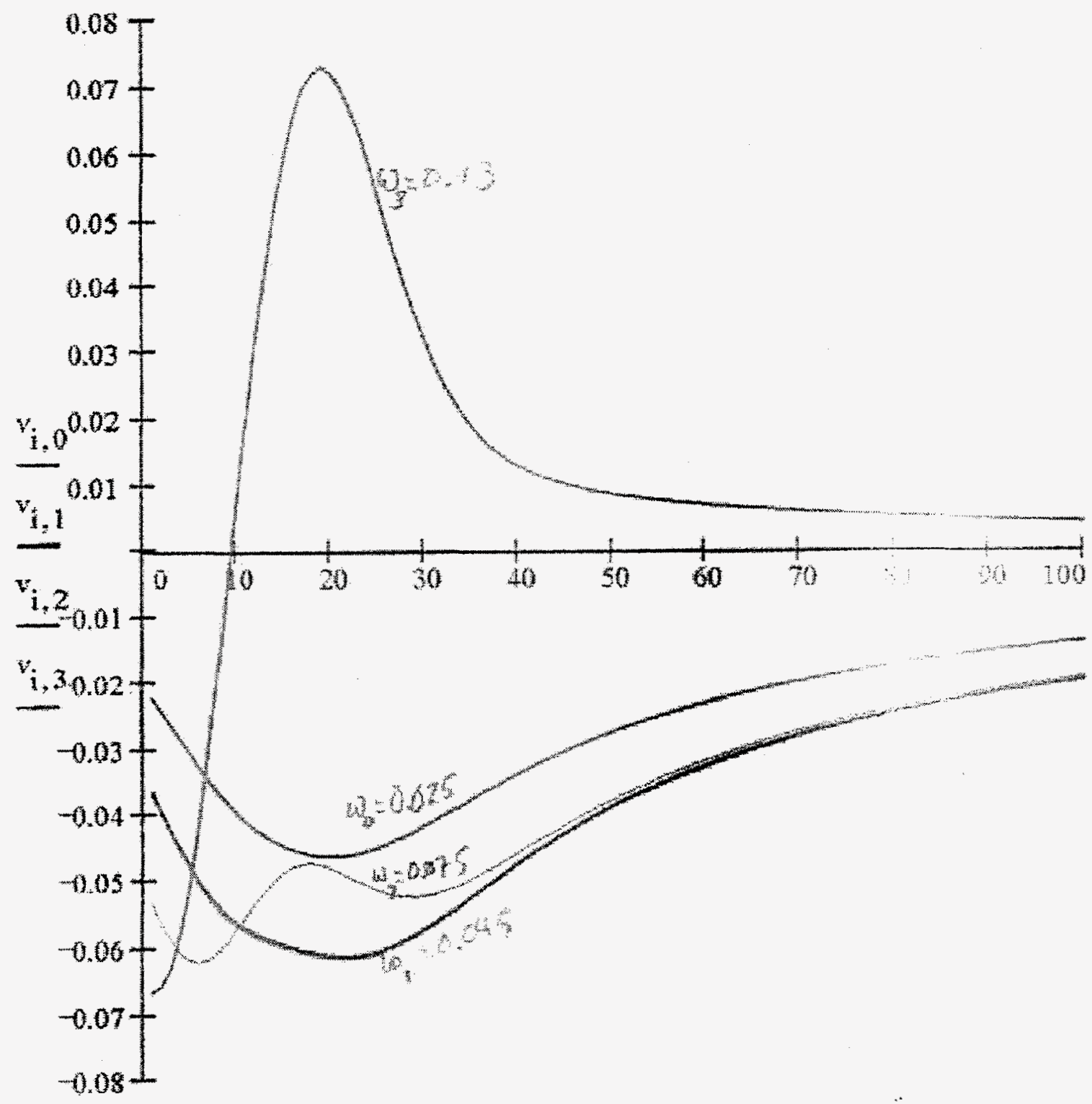

Fig. 1. Plot of depth ratio (log scale) vs. relative etch time (arbitrary units) Positive values of $v$ are etch stop regions. 


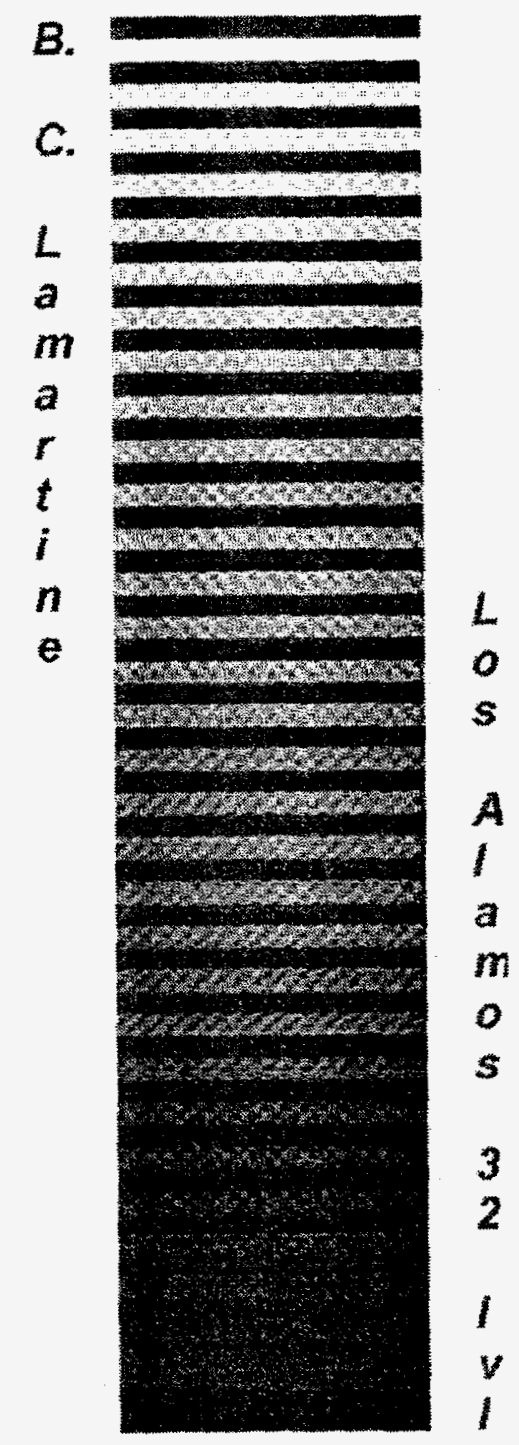

Fig. 2. Graphic representation of CAM file used to vary ion dose in striped regions. 


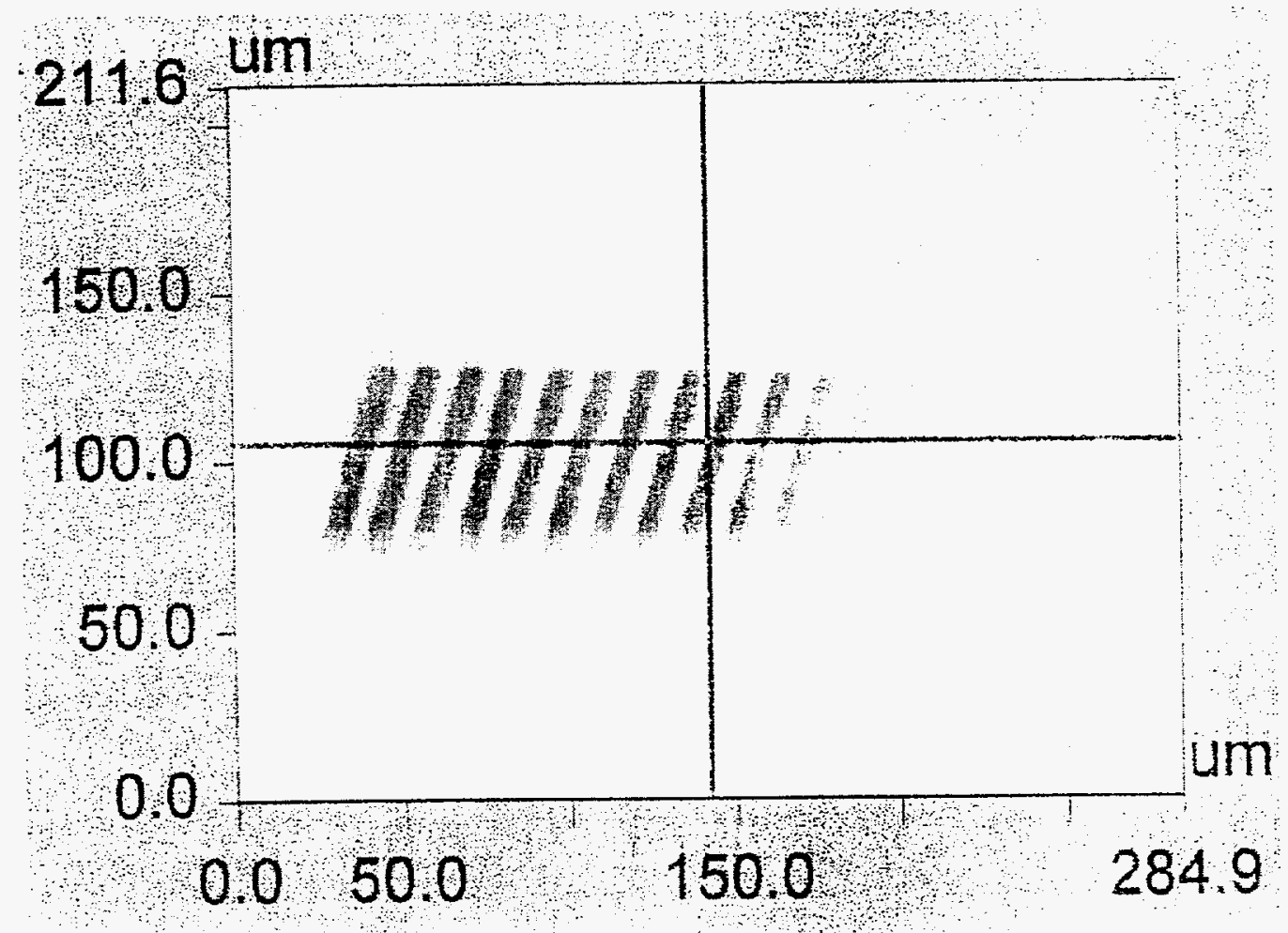

Fig. 3. Mirau depth interferogram of the region exposed by CAM control using the file depicted in figure 2. 


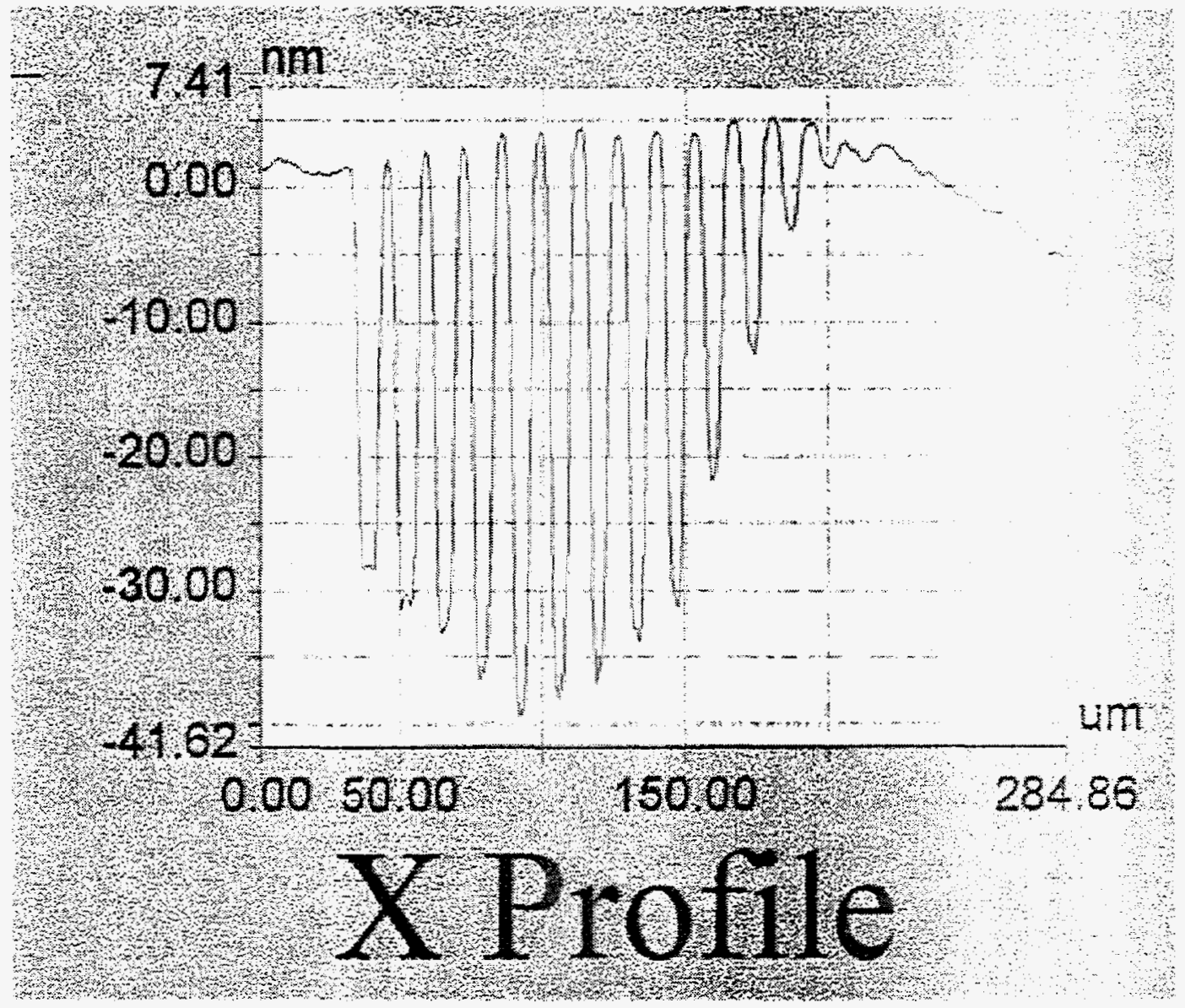

Fig. 4. Cross-section of the Mirau interferogram of Fig. 3. Note the regions of increasing and decreasing depth. 